\title{
Thrombospondin 2 Promotes IL-6 Production in Osteoarthritis Synovial Fibroblasts via the PI3K/ AKT/NF-KB Pathway
}

\author{
Chun-Han Hou' \\ Chih-Hsin Tang ${ }^{2-5}$ \\ Po-Chun Chen (iD) ${ }^{5-7}$ \\ Ju-Fang Liu ${ }^{7,8}$
}

'Department of Orthopedic Surgery, National Taiwan University Hospital, Taipei City, Taiwan; ${ }^{2}$ School of Medicine, China Medical University, Taichung, Taiwan; ${ }^{3}$ Graduate Institute of Biomedical Science, China Medical University, Taichung, Taiwan; ${ }^{4}$ Chinese Medicine Research Center, China Medical University, Taichung, Taiwan; ${ }^{5}$ Department of Biotechnology, College of Health Science, Asia University, Taichung, Taiwan; ${ }^{6}$ Translational Medicine Center Shin-Kong Wu Ho-Su Memorial Hospital, Taipei City, Taiwan; ${ }^{7}$ Department of Medical Research, China Medical University Hospital, China Medical University, Taichung, Taiwan; ${ }^{8}$ School of Oral Hygiene, College of Oral Medicine, Taipei Medical University, Taipei, Taiwan
Correspondence: Ju-Fang Liu; Po-Chun Chen

School of Oral Hygiene, College of Oral Medicine, Taipei Medical University, No. 250 Wu-Hsing Street, Taipei, I I03 I, Taiwan

Tel +8862-2736I66I Ext. 5II0

Email jufangliu@tmu.edu.tw;

blibra1002@gmail.com
Background: It is known that osteoarthritis (OA) pathogenesis involves inflammation that drives pathologic changes and that the matricellular protein, thrombospondin-2 (TSP2), is involved in angiogenesis, carcinogenesis, and inflammation. However, how TSP2 contributes to OA inflammatory processes is unclear.

Objective: The aim of current study was to elucidate whether TSP2 could promote interleukin6 (IL-6), a pro-inflammatory cytokine, expression in osteoarthritis synovial fibroblasts (OASFs).

Methods: The synovial fibroblasts isolated from osteoarthritis and healthy donors were incubated with recombinant TSP2 to evaluate its effect in OA pathogenesis. The SFs were incubated with recombinant TSP2, followed by determining the IL- 6 expression by qPCR and Western blot. After SFs were incubated with TSP2 for different time interval, the Western blot was performed to investigate the activation of signal pathway. The different strategies including neutralizing antibodies, siRNAs, and chemical inhibitors were used to discover the signal transduction in response to TSP2 incubation in OASFs. To evaluate the therapeutic potential of TSP2 in osteoarthritis, the anterior cruciate ligament transection (ACLT) in SD rats was performed in the presence or absence of TSP neutralizing antibody treatment.

Results: Our investigations have revealed that TSP2 promoted IL- 6 expression in OASFs in a dose-dependent manner, especially in 30 and $100 \mathrm{ng} / \mathrm{mL}$ concentration $(\mathrm{p}<0.05)$. Using different strategies including neutralizing antibodies, siRNAs, and chemical inhibitors, all of which attenuated signal pathway components in OASFs, we found evidence for the involvement of integrin $\alpha_{\mathrm{v}} \beta_{3}$, PI3K, Akt, and NF- $\mathrm{BB}$ in TSP2-mediated upregulation of IL-6 ( $\mathrm{p}<$ 0.05). Finally, in the result of rat ACLT surgical model, we found that TSP2 neutralizing antibody had protective effects in cartilage destruction during OA progression.

Conclusion: Thrombospondin-2 palys an important role in osteoarthritis pathogenesis and provides an opportunity to deal with osteoarthritis.

Keywords: TSP2, osteoarthritis, integrin $\alpha_{\mathrm{v}} \beta_{3}$, IL-6

\section{Introduction}

The degenerative joint disease, osteoarthritis (OA), affects mainly people from middle-age onwards ${ }^{1}$ and most often afflicts the hands and knees, hips, and spine. $^{2,3}$ There are also earlier forms of OA. The multifactorial etiology of OA includes occupational and nonoccupational (ie, joint injury, obesity, aging, and heredity) factors. ${ }^{4,5} \mathrm{OA}$ joints are characterized by severe synovial inflammation, abrasive wear at the cartilage surface, thickening of the subchondral bone, and the development of osteophytes. ${ }^{6}$ Besides this, OA has been also described as a chronic inflammatory disease caused by an increase of inflammatory mediators. ${ }^{7}$ Major 
contributing factors to the pathogenesis of OA include the extracellular matrix (ECM) degrading enzyme such as the matrix metalloproteinases (MMPs) and ADAMTS-5 (ADAM metallopeptidase with thrombospondin type 1 motif 5), the proinflammatory cytokines interleukin-1 beta (IL-1 $\beta$ ), IL-6, and tumor necrosis factor-alpha (TNF- $\alpha$ ), as well as Wnt signaling regulating bone formation and regeneration. ${ }^{8-11}$ Understanding the mechanisms responsible for the destruction of joint tissue in $\mathrm{OA}$ and identifying the key factors involved will identify new targets for therapy and enable the development of new therapies that not just treat the symptoms, but slow the disease progression.

Cartilage oligomeric matrix protein (COMP/thrombospondin [TSP]-5), a glycoprotein that belongs to the thrombospondin family, is one of the most studied markers of cartilage degradation as well as joint degeneration. ${ }^{12,13} \mathrm{An}$ elevated level of COMP/TSP5 was found in serum and synovial fluid and associated with the degree of cartilage destruction and disease progression in osteoarthritis. ${ }^{14-16}$ Besides COMP/TSP5, the other members of the thrombospondin family are also associated with osteoarthritis progression. For instance, increased levels of TSP1 expression were found in human cartilage with early OA, as well as substantially reduced TSP1 synthesis and TSP1 protein staining in severe OA, compared with normal cartilage. ${ }^{17}$ The other report showed that TSP1 exhibited protective effects against osteoarthritis by indirect interaction with adipose stem cells, subsequently reducing inflammation of chondrocytes. ${ }^{18}$ TSP4 expression was found to upregulate in OA keen cartilage and associated with disease severity. ${ }^{19}$ These evidence reveal that the TSP family, a matricellular protein with various functions, has an important role in the homeostasis of chondrocyte as well as in OA pathogenesis.

The loss of cartilage tissue in OA is due to the degradation of the ECM, which is influenced in part by a lack of the matricellular protein TSP2, an essential component in the proper assembly of the $\mathrm{ECM},{ }^{20}$ endothelial cell proliferation, migration, and differentiation. ${ }^{21-23}$ TSP2-null mice exhibit connective tissue abnormalities including lax tendons and ligaments, abnormal collagen fibrils in the skin and tendons, and prolonged bleeding times. ${ }^{24}$ Embryonic tissues from TSP2-null mice reveal TSP2 expression in chondrogenic, osteogenic, vasculogenic cells, dermal fibroblasts, and other connective tissueforming cells. ${ }^{25,26}$ In adult tissue, TSP2 is found almost solely in the pericellular environment of cells. ${ }^{24}$ Moreover, compared with normal littermates, increased numbers of endocortical osteoblasts in TSP2-null mice mean that they have thicker cortical bones, with higher endocortical bone formation rates and an overall increased periosteal mineralizing surface. ${ }^{27,28}$ Previous report provided evidence that TSP2 served as regulator of inflammation in rhumatoid arthritis. ${ }^{29}$ However, this study only provided pathologic evidence and clinical revelance of TSP2 in rhumatoid arthritis.

Although many evidences support a pathogenic role for the other members among the TSP family in arthritis, more remains to be clarified as to the molecular connections between TSP2 and arthritis. Here, we found increased expression of TSP2 in OASFs compared with NSFs. We also verified the therapeutic response of TSP2 neutralizing antibody by using in vivo OA model. These evidence provided potential for clinical application of TSP2 in OA.

\section{Materials and Methods \\ Materials}

Invitrogen (Carlsbad, CA, USA) supplied fetal bovine serum (FBS; Cat. No. 26140079), Dulbecco's Modified Eagle Medium (DMEM; Cat. No. 12100046), and Lipofectamine 3000 (Cat. No. L3000015). Corning (NY, USA) supplied all cell culture materials including dishes and well plates. Millipore (Billerica, MA, USA) supplied polyvinylidene difluoride (PVDF) membranes and chemiluminescent HRP Substrate (ECL). Santa Cruz Biotechnology (Santa Cruz, CA, USA) supplied antibodies against PI3K (Cat. No. sc-1637), Akt (Cat. No. sc-5298), IкB (Cat. No. sc-1643), IKK $\alpha / \beta$ (Cat. No. sc-7607), p65 (Cat. No. sc-8008), integrin $a_{v} b_{3}$ (Cat. No. sc-7312) and $\beta$ actin (Cat. No. sc-47778). The antibodies against phosphoPI3K (Tyr ${ }^{458 / 199}$ ) (Cat. No. \#4228), phospho-Akt ( $\operatorname{ser}^{473}$ ) (Cat. No. \#9271), phospho-IKK $\alpha / \beta$ ( $\operatorname{ser}^{176 / 180}$ ) (Cat. No. \#2697), phospho-IкB $\alpha\left(\operatorname{ser}^{32 / 36}\right)$ (Cat. No. \#9246) and phospho-p65 $\left(\operatorname{ser}^{536}\right.$ ) (Cat. No. \#3033) were provided by Cell Signaling and Neuroscience (Danvers, MA, USA). Sigma-Aldrich (St. Louis, MO, USA) provided the chemical inhibitors used in current study, including Wortmannin (Cat. No. W1628), LY294002 (Cat. No. L9908), AktI (Cat. No. A6730), TPCK (Cat. No. T4376), and PDTC (Cat. No. P8765). R\&D Systems (Minneapolis, MN, USA) supplied recombinant human TSP2 (Cat. No. 1635-T2-050). shRNAs for integrins $\alpha_{\mathrm{v}}$ and $\beta_{3}$ and their respective controls were obtained from the National RNAi Core Facility Platform (RNAi Core, Academia Sinica, Taiwan). 
Stratagene (La Jolla, CA, USA) provided the NF-кB luciferase plasmid. Dr. Wen-Mei $\mathrm{Fu}$ (National Taiwan University, Taipei, Taiwan) kindly gifted the dominantnegative mutants of p85 and Akt. Promega (Madison, MA, USA) supplied the pSV- $\beta$-galactosidase vector and the luciferase assay kit. The chemicals used in the current research were supplied by Sigma-Aldrich (St. Louis, MO, USA).

\section{Clinical Samples}

The Institutional Review Board (IRB) of Shin Kong Wu Ho-Su Memorial Hospital (Approval No. 20161209R) and China Medical University (Approval No. CMUH108REC3-039) granted study approval and each study participant provided written informed consent. All methods were conducted in accordance with the provisions of the Declaration of Helsinki, as well as the IRB's guidelines and regulations. Clinical samples were collected from patients meeting the following inclusion criteria: (1) aged over 20 years presenting with an accidental or sports injury requiring joint replacement and repair; or (2) degenerative arthritis. Exclusion criteria specified patients who did not satisfy either of these two categories. Synovial specimens were collected from donors with OA who have knee replacement surgery (OASFs) and nonarthritic synovial tissues obtained from healthy donors undergoing arthroscopy after trauma/joint derangement (NSFs).

\section{Cell Cultures}

The NSFs and OASFs cells were collected and maintained according to previous study procedures. ${ }^{30-32}$ Fresh synovial tissues were finely minced and digested in DMEM containing $2 \mathrm{mg} / \mathrm{mL}$ type II collagenase (Sigma-Aldrich, St. Louis, MO, USA) for $4 \mathrm{~h}$ at $37^{\circ} \mathrm{C}$ and under $5 \% \mathrm{CO}_{2}$. After incubation with collagenase, the synovial fibroblasts were harvested by filtering through $70 \mu \mathrm{M}$ nylon filters, centrifugation, and maintained in DMEM supplied with $10 \% \mathrm{FBS}, 100 \mu \mathrm{g} / \mathrm{mL}$ streptomycin, and $100 \mathrm{U} / \mathrm{mL}$ penicillin. The cells were kept in a $\mathrm{CO}_{2}$ incubator at $37^{\circ} \mathrm{C}$ and $5 \% \mathrm{CO}_{2}$. As previous study described, ${ }^{33}$ after isolating the cells from synovial tissues, the cells were characterized by immunofluorescence staining using antibody against vimentin, a typical fibroblast's marker. More than 95\% of the cells were fibroblasts. The synovial fibroblasts from passages of four to nine were used for the experiments.

\section{RNA Extraction and Quantitative Real-Time PCR}

The RNA of the treated cells was extracted by an easy-

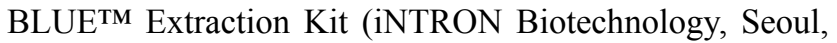
Korea). The total $2 \mu \mathrm{g}$ RNA was used to synthesize cDNA by reverse transcription reaction using M-MLV Reverse Transcriptase (Invitrogen, Carlsbad, CA, USA). SYBR Green Mastermix (KAPA Biosystem, Woburn, MA, USA) was used to perform quantitative real-time PCR (qPCR) analysis on StepOnePlus ${ }^{\mathrm{TM}}$ Real-Time PCR System (Applied Biosystems, Foster City, CA, USA). The running protocol was $10 \mathrm{~min}$ at $95{ }^{\circ} \mathrm{C}, 15 \mathrm{~s}$ at $95{ }^{\circ} \mathrm{C}$ for 40 cycles, and finally $60 \mathrm{~s}$ at $60{ }^{\circ} \mathrm{C}$. The primers used for detecting target genes were obtained from SigmaAldrich (St. Louis, MO, USA). Relative expressions of target genes were normalized to endogenous control GAPDH by using $2^{\Delta \Delta C t}$ Method. All data shown were representative of three independent experiments. The sequence information of primers was provided in Supplementary Table 1.

\section{Western Blot}

Total proteins were extracted from the cells treated as indicated conditions by using RIPA buffer. Protein quantification and normalization were conducted by using a Thermo Scientific Pierce BCA Protein Assay Kit (Thermo Fisher Scientific Inc., Waltham, USA). Proteins were loading to SDS-PAGE and running with $100 \mathrm{~V}$ for 90 mins, followed by transferring to PVDF membranes. The membranes were blocked with blocking buffer containing 5\% BSA for $1 \mathrm{~h}$ at room temperature, followed by incubated the membranes with primary antibodies $(1: 1000)$ overnight at $4^{\circ} \mathrm{C}$. After 3 washes by TBST, the membranes were incubated with horseradish peroxidase (HRP)-conjugated secondary antibodies (1:5000) for $1 \mathrm{~h}$ at room temperature. The membranes were stained by Amersham ${ }^{\mathrm{TM}}$ ECL $^{\mathrm{TM}}$ Western Blotting Detection Reagents (GE Healthcare Life Sciences, Marlborough, MA, USA) and monitored by using a UVP ChemiDoc-It Imaging System (UVP Inc., Upland, CA, USA).

\section{Transfection and Reporter Gene Assay}

The reporter gene assay was used to monitor NF- $\mathrm{kB}$ transcriptional activity as described previously. ${ }^{34}$ Briefly, cells grown in 24 well plates were transfected with $0.8 \mu \mathrm{g}$ reporter vector including NF- $\mathrm{KB}$ response element and 
$0.4 \mu \mathrm{g} \quad \beta$-galactosidase expression vector by Lipofectamine ${ }^{\circledR} 3000$ (LF3000; Invitrogen). 24-hour posttransfection, the cells were further treated with the indicated condition. Finally, the cells were lysed by reporter lysis buffer (Promega, Madison, WI, USA). The $20 \mu \mathrm{L}$ lysates were mixed with $80 \mu \mathrm{L}$ luciferase assay buffer (Promega), followed by detection of luminescence by using a microplate luminometer. The activity of $\beta$ galactosidase was used to evaluate transfection efficiency and in normalization of luciferase activity.

\section{Immunofluorescence Staining}

The cells grown in 8 well chamber slides were treated with the indicated condition. For immunofluorescence staining, the cells were fixed by $4 \%$ paraformaldehyde for 30 mins at room temperature, incubated in BSA blocking buffer containing $0.05 \%$ Triton $\mathrm{X}-100$ for 30 mins at room temperature. Subsequently, the cells were incubated with $\mathrm{p} 65$ antibody $(1: 100)$ overnight at $4^{\circ} \mathrm{C}$. After 3 times washing with PBS, the cells were further incubated with FITCconjugated secondary antibody (1:100) for $1 \mathrm{~h}$ at room temperature (Leinco Technology Inc., St. Louis, MO, USA). Finally, the immunofluorescence signal was monitored by using a Nikon Ti2-E microscope system.

\section{ACLT Animal Model}

All animal procedures were approved by the Institutional Animal Care and Use Committee (IACUC) of Shin Kong $\mathrm{Wu} \mathrm{Ho}-\mathrm{Su}$ Memorial Hospital (Approval No. MOST1060009). All animal experimental procedures followed the Guide for the Care and Use of Laboratory Animals (Council of Agriculture, Executive Yuan, Taiwan). All experimental procedures were performed by two of the study authors, PC Chen and JF Liu, who have excellent experience in performing and replicating this animal model. The small sample size was chosen because the response of TSP2 neutralized antibody was investigated in OA animal model first time. A total of 25 male Sprague-Dawley (SD) rats (8 weeks) were purchased from the National Laboratory Animal Center (Taipei, Taiwan) and used for this study. The rats were randomly assigned to different groups; a) sham operation $(\mathrm{n}=7)$, b) ACLT operation without treatment $(\mathrm{n}=7)$, c) ACLT operation with TSP2 neutralizing antibody treatment $(\mathrm{n}=7)$. Briefly, after animals were anesthetized with inhaled isoflurane and the joint capsules were opened, the ACL fibers were transected with a scalpel and the entire medial meniscus was excised using a medial parapatellar mini-arthrotomy.
After surgery, the joints were washed with sterile PBS and sutured. The rats received 7 days of ampicillin treatment $(50 \mathrm{mg} / \mathrm{kg})$. The 4 rats were excluded because of the poor wound healing after surgery. One week later, they were administered an intra-articular injection of PBS $(50 \mu \mathrm{L})$ containing a TSP2 neutralizing antibody $(10 \mu \mathrm{g} / \mathrm{mL})$; this was repeated after 1 week. All rats were allowed to move freely in plastic cages and were sacrificed 4 weeks after the ACLT procedure. PC Chen and JF Liu, who performed the operation were the only investigators aware of the experiment allocation. The research assistant (unaware of treatment) was responsible for the animal sacrifice, tissue collection, and histological analysis including Safranin $\mathrm{O} /$ fast green staining, immunohistochemistry staining, and ORASI score.

\section{Histological Analysis}

Paraffin-embedded sections were prepared from sacrificed rats. The sections were subjected to Safranin O/fast green staining to evaluate cartilage degradation, or incubated with a specific antibody against IL-6, as per our previous protocol. ${ }^{22}$ IL-6 antibody in the sections was detected by the NovoLink Polymer Detection Systems kit (Leica Biosystems, Wetzlar, Germany), according to the manufacturer's protocol.

For Safranin O/fast green staining, briefly, the sections were stained with Safranin O/fast green, hematoxylin, and eosin to investigate the histopathological changes of all experiment groups under a light microscope. The cartilage destruction was evaluated according to the OARSI score system established by the International Association for Osteoarthritis Research. ${ }^{35}$ The OARSI score system includes 6 grades (Grade $0=$ no cartilage degeneration; Grade $1=$ Minimal degeneration, 5-10\% of the total projected cartilage area affected by matrix or chondrocyte loss; Grade 2 = Mild degeneration, 11-25\% affected; Grade 3 = Moderate degeneration, 26-50\% affected; Grade $4=$ Marked degeneration, 51-75\% affected; Grade $5=$ Severe degeneration, greater than $75 \%$ affected). The scoring was evaluated blindly by two individuals and the scores were averaged to minimize observer bias.

\section{Statistical Analysis}

Statistical data were analyzed using SigmaPlot version 12.0 (Systat Software, Inc., San Jose, CA). All values reported are means \pm standard deviations (S.D) of independent experiments. Statistical analysis of two samples was performed 
using the Student's $t$-test. In the case of the experiment groups more than two groups, statistical analysis was performed using one-way analysis of variance (ANOVA) with the Fisher's Least Significant Difference (LSD) post-hoc test. In all cases, $\mathrm{p}<0.05$ presented statistical significance.

\section{Results}

\section{TSP2 Induced Significant Increases in IL-6 Expression}

As shown in Figure 1A and B, evidence from Western blot and qPCR assays reveals higher levels of TSP2 protein and mRNA expression in OASFs than in human normal synovial fibroblasts (NSFs). As previous research has shown high quantities of proinflammatory cytokines (IL-1 $\beta$, IL-6, and TNF- $\alpha$ ) as well as endothelial adhesion molecules (ICAM-1 and VCAM-1) in OA fibroblast lines, ${ }^{36}$ consistent with our resuts (Supplementary Figure 1). Therefore, we hypothesized that the same phenomenon might be observed in TSP2-directed OA pathogenesis. The levels of IL-6 expression were significantly higher than those for all other molecules (Figure 1D), whereas TSP2 had no effect upon IL-6 expression in NSFs (Figure 1C). TSP-induced increases in IL-6 expression were concentration-dependent (Figure 1E and F). These data suggest that OASFs are more sensitive than normal SFs to TSP2 and that TSP2 effectively increases IL-6 production in OASFs.

\section{A TSP2/Integrin $\alpha_{v} \beta_{3}$ Interaction Was Linked to IL-6 Expression in OASFs}

TSP2 is reported to interact with various integrins to exert its biological functions, including integrin $\alpha_{\mathrm{v}} \beta_{3},{ }^{22,37,38} \alpha_{4} \beta_{1}{ }^{39}$ and $\beta_{1}{ }^{40}$ The TSP2 arginine-glycine-aspartic acid sequence interacts with cell-associated integrin $\alpha_{v} \beta_{3}$ and heparan sulfate proteoglycans and also binds to the low-density lipoprotein receptor-related protein that modulates TSP2 concentrations in the pericellular environment via endocytotic and lysosomal protein degradation processes. ${ }^{41}$ Our results found that both basal expression levels of integrin $\alpha_{v}$ and $\beta_{3}$ were higher in OASFs than NSFs (Figure 2A), suggesting their important role in OA pathogenesis. We, therefore, examined the effect of integrin $\alpha_{v} \beta_{3}$ neutralization upon TSP2-induced increases in IL-6 expression in human OASFs. Our data show that the integrin $\alpha_{v} \beta_{3}$ antibody
A

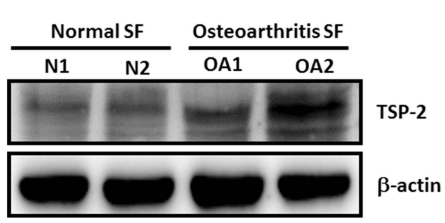

D

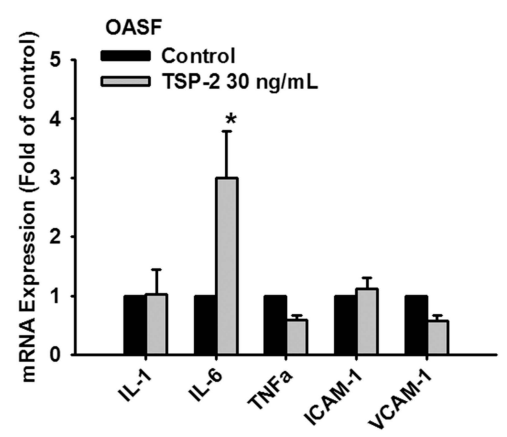

B

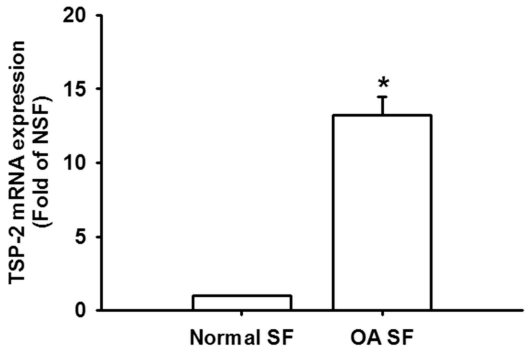

$\mathbf{F}$

E

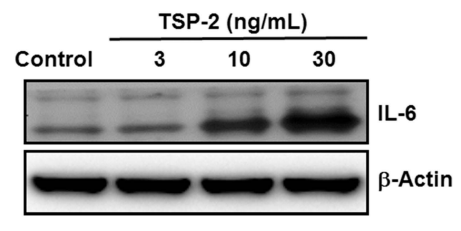

C
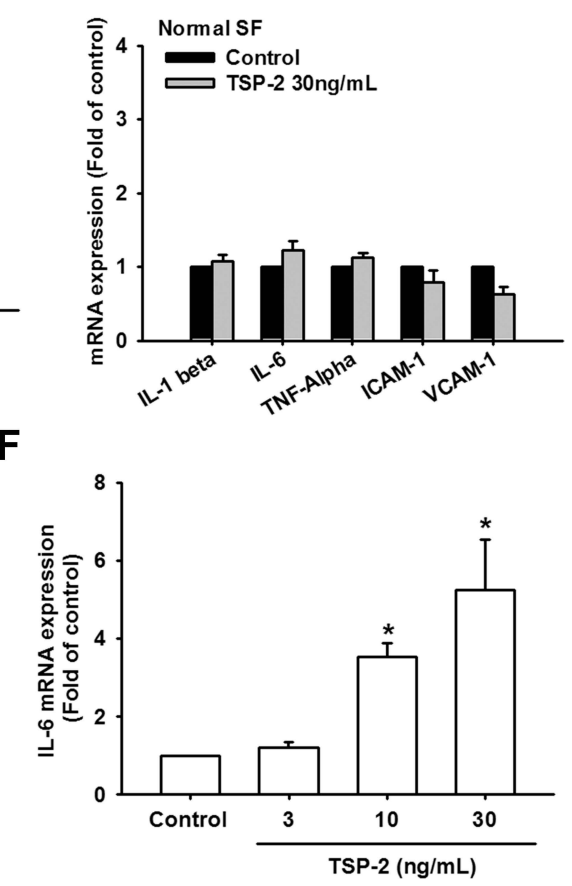

Figure I TSP2 is associated with IL-6 expression level in OASFs. (A and B) OASFs obtained from 5 healthy donors and 5 patients with OA were subjected to perform Western blot and qPCR assays for evaluating TSP2 expression level. (C and D) OASFs and normal SFs underwent $24 \mathrm{~h}$ of TSP2 incubation. The mRNA expression levels of IL-I $\beta$, IL-6, TNF- $\alpha$, ICAM-I, and VCAM-I were investigated by qPCR assay $(n=5)$. (E) OASFs were treated with different doses of TSP2 for $24 \mathrm{~h}$ before collection of cell lysates. IL-6 protein levels were determined by Western blot analysis $(n=5)$. (F) OASFs were treated with different doses of TSP2 for 24 h, followed by determining IL-6 mRNA expression by qPCR $(n=5)$. Results are expressed as the mean \pm S.D. ${ }^{*} p<0.05$ compared with untreated controls.

Abbreviations: SF, synovial fibroblast; TSP-2, thrombospondin-2; OASF, osteoarthritis synovial fibroblast; IL, interleukin; ICAM, intercellular adhesion molecule; VCAM, vascular cell adhesion molecule. 

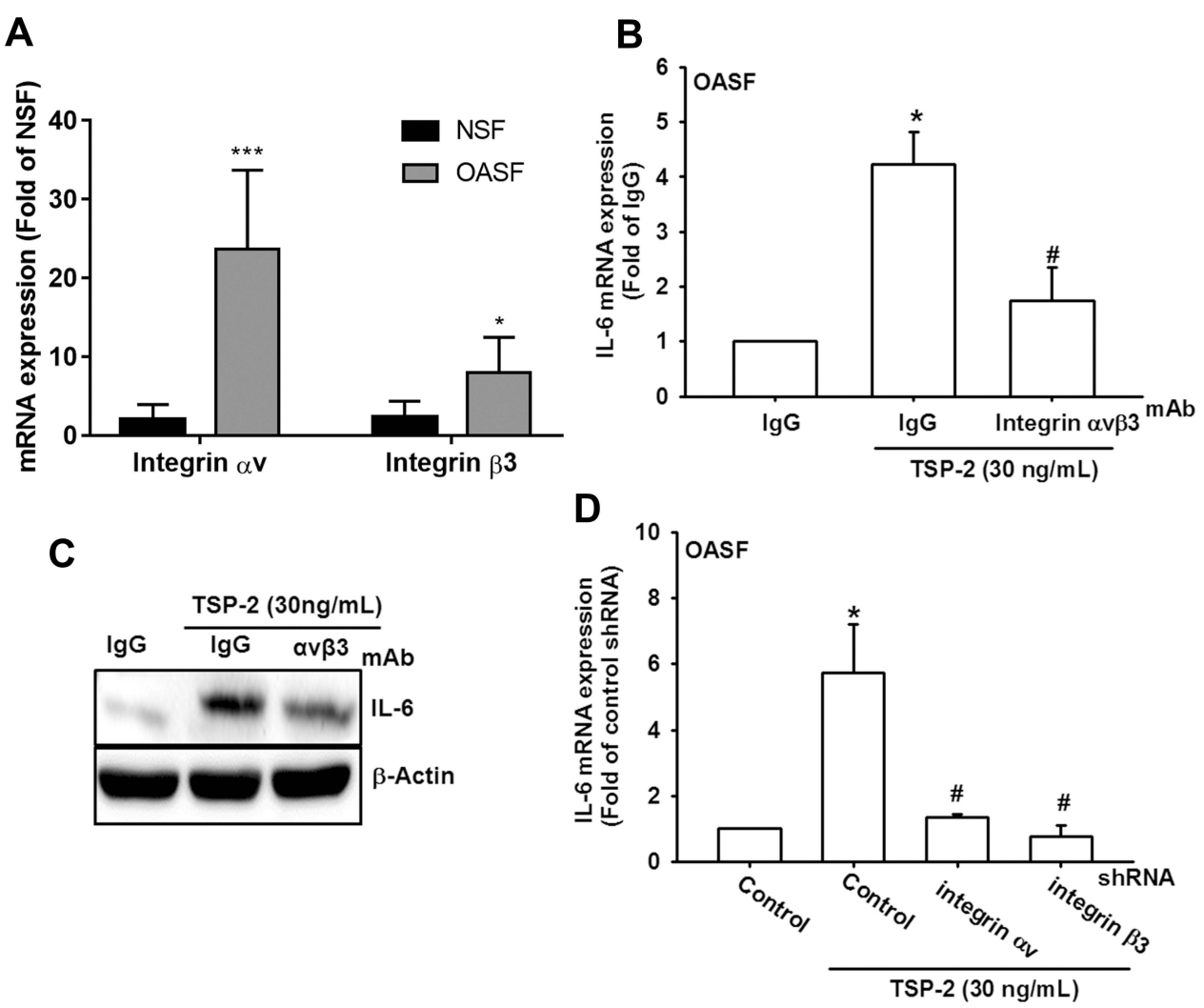

Figure 2 Integrin $\alpha_{v} \beta_{3}$ contributes to TSP2-promoted IL-6 expression in OASFs. (A) The total RNA was extracted from NSFs and OASFs, followed by examining expressions of integrin $\alpha v$ and $\beta 3$ by qPCR. (B) Cells were incubated with lgG or integrin $\alpha_{v} \beta_{3}$ neutralizing antibodies for 30 min, followed by incubation with TSP2 (30 ng/ $\mathrm{mL}$ ) treatment for $24 \mathrm{~h}$. The IL-6 mRNA expression was evaluated by qPCR. (C) Cells were incubated with lgG or integrin $\alpha_{v} \beta_{3}$ neutralizing antibodies for 30 min, followed by TSP2 $(30 \mathrm{ng} / \mathrm{mL})$ treatment for $24 \mathrm{~h}$. The protein expression of IL-6 were examined by Western blot. (D) OASFs transfected with integrin $\alpha_{v}$ and $\beta_{3}$ shRNAs were treated with TSP2 $(30 \mathrm{ng} / \mathrm{mL})$ for $24 \mathrm{~h}$. The expression patterns of IL- 6 were evaluated by qPCR. Results are expressed as the mean \pm S.D. ( $\geq 25)$; In $(\mathbf{A}) * * * \mathrm{p}<0.00 \mathrm{I}$ and $* \mathrm{p}$ $<0.05$ compared with NSFs group; In other figures, ${ }^{*} \mathrm{p}<0.05$ compared with IgG control groups, and ${ }^{\#} \mathrm{P}<0.05$ compared with the TSP2-treated group.

Abbreviations: NSF, normal synovial fibroblasts; OASF, osteoarthritis synovial fibroblast; IgG, immunoglobulin G; TSP-2, thrombospondin-2; IL-6, interleukin-6.

substantially inhibited such increases (Figure 2B and C). This process was dramatically inhibited when OASFs were transfected with integrin $\alpha_{v}$ and integrin $\beta_{3}$ shRNAs (Figure 2D). Thus, it appears that the effects of TSP2 upon IL-6 expression occur via the activation of integrin $\alpha_{v} \beta_{3}$.

\section{TSP2-Mediated IL-6 Production Involves PI3K/Akt Signaling}

The PI3K/Akt signaling pathway is one of several that are activated by the engagement of integrin $\alpha_{v} \beta_{3}$ with its ligand. $^{42}$ Furthermore, IL-6 expression in prostate cancer cells and human lung fibroblasts is mediated by PI3K/Akt signaling. $^{43,44}$ We, therefore, examined whether TSP2induced increase of IL-6 expression involves PI3K and Akt signaling. Pretreatment with LY294002, Wortmannin, and AktI all markedly reduced the effects of TSP2 upon IL-6 expression in OASFs (Figure 3A-C), while TSP2 treatment significantly increased p85 and Akt phosphorylation (Figure 3D). The OASFs which transfected with a p85 or an Akt dominant-negative (DN) mutant showed obvious inhibition of TSP-2-induced IL-6 expression (Figure 3E). Thus, blocking PI3K and Akt activity appears to inhibit TSP2-mediated IL-6 expression. Moreover, these findings indicate that TSP2 stimulates IL- 6 production via the activation of integrin $\alpha_{v} \beta_{3}$, which subsequently activates the PI3K/ Akt signaling pathway in OASFs.

\section{NF- $\kappa B$ is Involved in TSP2-Induced Stimulation of IL-6 Expression}

NF- $\kappa \mathrm{B}$ activation can induce IL- 6 in various cell types. ${ }^{45}$ To examine whether NF- $\kappa \mathrm{B}$ activity in the signaling pathway mediates TSP2-induced increases in IL-6 expression, OASFs were pretreated separately with the NF- $\kappa \mathrm{B}$ inhibitor (PDTC; $5 \mu \mathrm{M}$ ) and I $\mathrm{B}$ protease inhibitor (TPCK; 5 $\mu \mathrm{M})$ before TSP2 application. The data showed that pretreatment with inhibitors of NF- $\kappa \mathrm{B}$ signal cascade dramatically abrogated IL-6 mRNA and protein expression in response to TSP2 incubation (Figure 4A and B). 
A

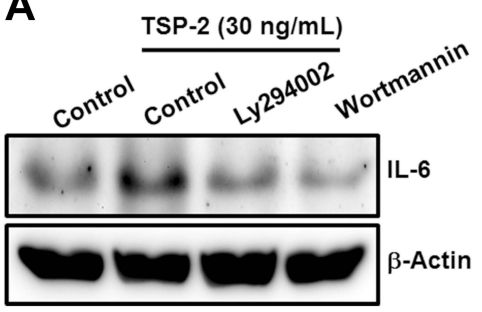

B

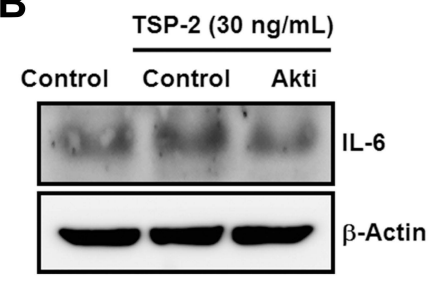

C

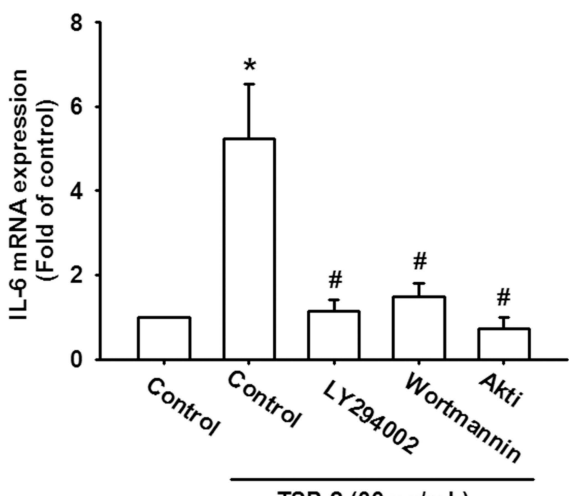

D

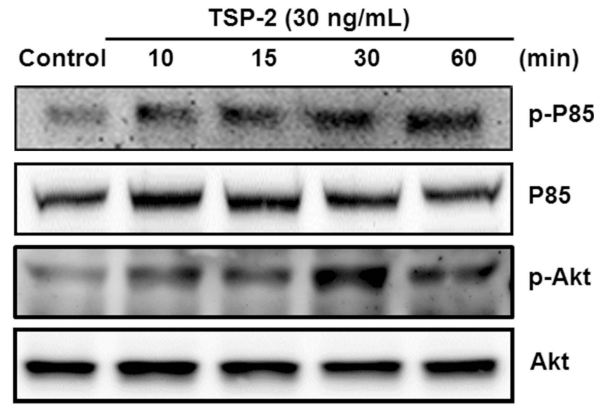

$\mathbf{E}$

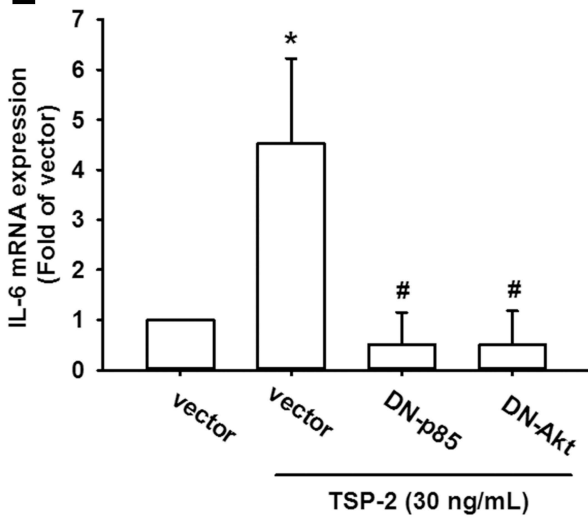

Figure 3 PI3K/Akt participates TSP2-promoted IL-6 production in OASFs. (A-C) OASFs were incubated with LY294002 (5 $\mu$ M), Wortmannin (0.5 $\mu$ M), or Aktl (5 $\mu$ M) for $30 \mathrm{~min}$, then stimulated for $24 \mathrm{~h}$ with TSP2 $(30 \mathrm{ng} / \mathrm{mL})$. The expression levels of IL-6 were determined by Western blot and qPCR assays. (D) OASFs were stimulated with TSP2 (30 ng/mL) for the different time courses, and activation of p85 and Akt was monitored by detecting their phosphorylated form by Western blot analysis. (E) OASFs were transfected with PI3K and Akt mutants, then stimulated for $24 \mathrm{~h}$ with TSP2. The expression level of IL- 6 was evaluated by qPCR. Results are expressed as the mean \pm S.D. $\left(\mathrm{n} \geq 5\right.$ ). ${ }^{*} \mathrm{p}<0.05$ compared with controls; ${ }^{*} \mathrm{p}<0.05$ compared with the TSP2-treated group.

Abbreviations: TSP-2, thrombospondin-2; IL-6, interleukin-6; DN, dominant mutant.

Moreover, TSP2 treatment time-dependently upregulated $\mathrm{IKK} \alpha / \beta$, IkB $\alpha$, and p65 phosphorylation in OASFs (Figure 4C). Upon IKK $\alpha$ and IKK $\beta$ mutant transfection, TSP2-induced stimulation of IL-6 expression was significantly reduced in OASFs (Figure 4D).

Pretreatment with integrin $\alpha_{\mathrm{v}} \beta_{3}$ monoclonal antibody (mAb), LY294002, Wortmannin, and AktI all reversed the nuclear translocation of $\mathrm{p} 65$, which was induced by TSP2 incubation in OASFs (Figure 5A), and abolished phosphorylation of the NF- $\kappa \mathrm{B}$ signaling cascade (Figure $5 \mathrm{~B}$ ). We also found that TSP2 stimulated NF- $\kappa \mathrm{B}$ promoter activity (Figure 5C), which was abolished when the OASFs were pretreated with integrin $\alpha_{\mathrm{v}} \beta_{3} \mathrm{mAb}$, LY294002, Wortmannin, and AktI (Figure 5D). Our evidence suggests that TSP2-mediated increases of IL-6 expression in human OASFs are dependent upon integrin $\alpha v \beta 3$ and PI3K/Akt-NF- $\kappa$ B pathway activation.

\section{TSP2-Targeting Therapy Alleviates ACLT-Induced Osteoarthritis in vivo}

Finally, to confirm the therapeutic value of TSP2 in OA, IL-6 expression was assessed in the presence of TSP2 $\mathrm{mAb}$. The results indicated that TSP2 neutralizing antibody dose-dependently abolished IL-6 expression in OASFs (Figure 6A and B). Meanwhile, the ACLTinduced $\mathrm{OA}$ in rat model, ${ }^{46}$ an animal model suitable for evaluating OA pathogenesis, was conducted to evaluate whether TSP2 target therapy could alleviate OA progression in vivo. Our result showed that treatment with TSP2 neutralizing antibody attenuated articular cartilage 
A

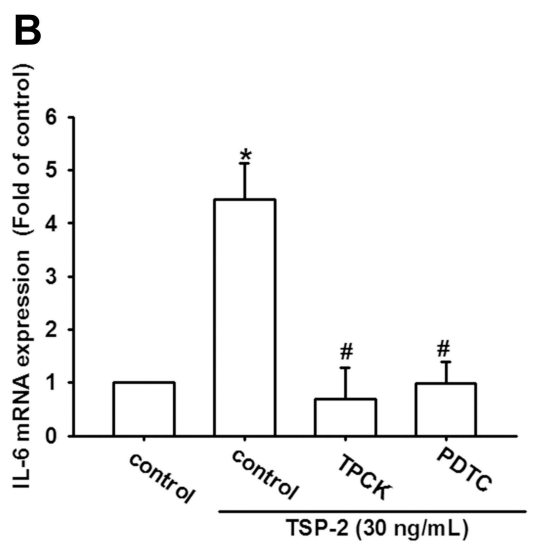

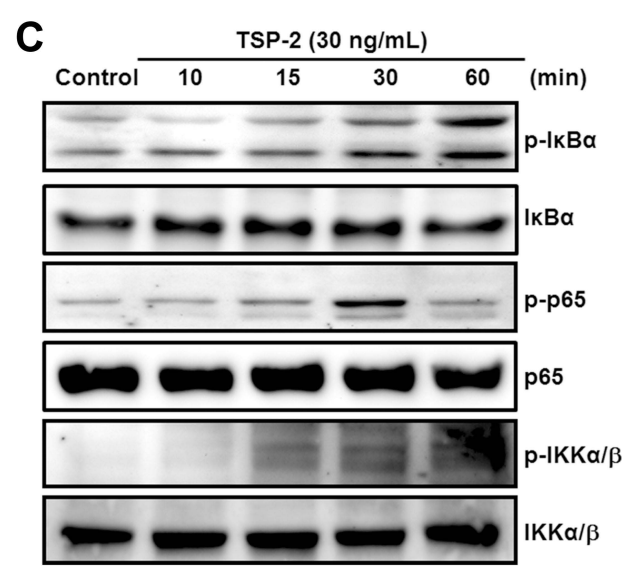

D

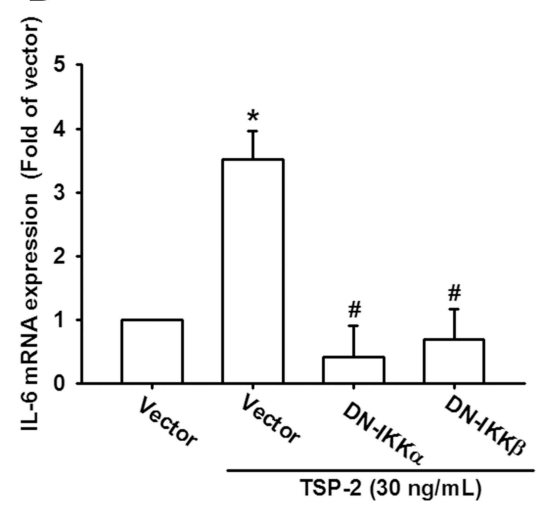

Figure 4 NF- $\kappa B$ is required for IL-6 production in response to TSP2 stimulation. (A and B) OASFs were incubated with PDTC (I0 $\mu$ M) or TPCK (I0 $\mu$ M) for 30 min, then stimulated with TSP2 $(30 \mathrm{ng} / \mathrm{mL})$ for $24 \mathrm{~h}$. The expression levels of IL-6 in OASFs were examined by Western blot and qPCR assays. (C) OASFs were stimulated with TSP2 $(30 \mathrm{ng} / \mathrm{mL})$ for the various time courses; the phosphorylated forms of IKK $\alpha / \beta$, IKB $\alpha$, and p 65 were monitored by Western blot analysis. (D) OASFs transfected with IKK $\alpha$ and IKK $\beta$ mutants were stimulated with TSP2 $(30 \mathrm{ng} / \mathrm{mL})$ for $24 \mathrm{~h}$. IL-6 expression was investigated by qPCR. Results are expressed as the mean \pm SD ( $\geq 5)$. * $<0.05$ compared with controls; ${ }^{\#} \mathrm{p}<0.05$ compared with the TSP2-treated group.

Abbreviations: TSP-2, thrombospondin-2; IL-6, interleukin-6; DN, dominant mutant.

degradation and IL-6 expression, as proved by Safranin O/ fast green staining and immunohistochemistry respectively (Figure 6C-E), demonstrating the therapeutic potential of TSP2 in OA progression in vivo.

\section{Discussion}

TSP2 was proposed as prognosis marker in liver fibrosis, ${ }^{47,48}$ non-alcoholic fatty liver disease, ${ }^{49}$ and different cancers. ${ }^{50-53}$ This study demonstrates that TSP2 is an important player in OA pathogenesis, with a positive correlation observed between TSP2 expression and synovial tissue inflammation, suggesting TSP2 could been developed as novel osteoarthritis marker. The pre-clinical experiments, which utilized TSP2 neutralizing antibody to ameliorate cartilage destruction in OA animal model, also showed the promising response. The results provided therapeutic opportunity of TSP2 in OA treatment.

Evidence implicates TSP2 in the regulation of various biological processes, such as thrombosis, ${ }^{54}$ angiogenesis, ${ }^{55}$ proteolytic enzyme release, control of inflammatory cell influx, and activation of the inflammatory response. ${ }^{56,57}$ Previous research has demonstrated TSP involvement in OA pathogenesis, such as TSP $1,{ }^{17}$ and a positive correlation between levels of TSP4 protein expression and disease severity. ${ }^{19}$ Moreover, TSP2 displays antiangiogenic activity and suppresses autoimmune inflammation in RA synovial tissue. ${ }^{29}$ COMP/TSP5 is also a well-established cartilage destruction marker in osteoarthritis. ${ }^{58}$ Several reports have proposed that COMP/TSP5 is a promising diagnostic and prognostic marker, as well as disease severity. COMP/TSP5 has shown promise as a diagnostic and prognostic indicator and as a marker of the disease severity and the effect of treatment. ${ }^{59}$ COMP/TSP5 was proved to exert its biological function by interaction with integrin $\alpha_{v} \beta_{3}$ on chondrocytes, ${ }^{60}$ which in accordance with our current finding that TSP2 promoted IL- 6 expression by binding to integrin $\alpha_{v} \beta_{3}$. Interestingly, we found expression levels of integrin $\alpha_{\mathrm{v}}$ and $\beta_{3}$ were higher in OASFs 


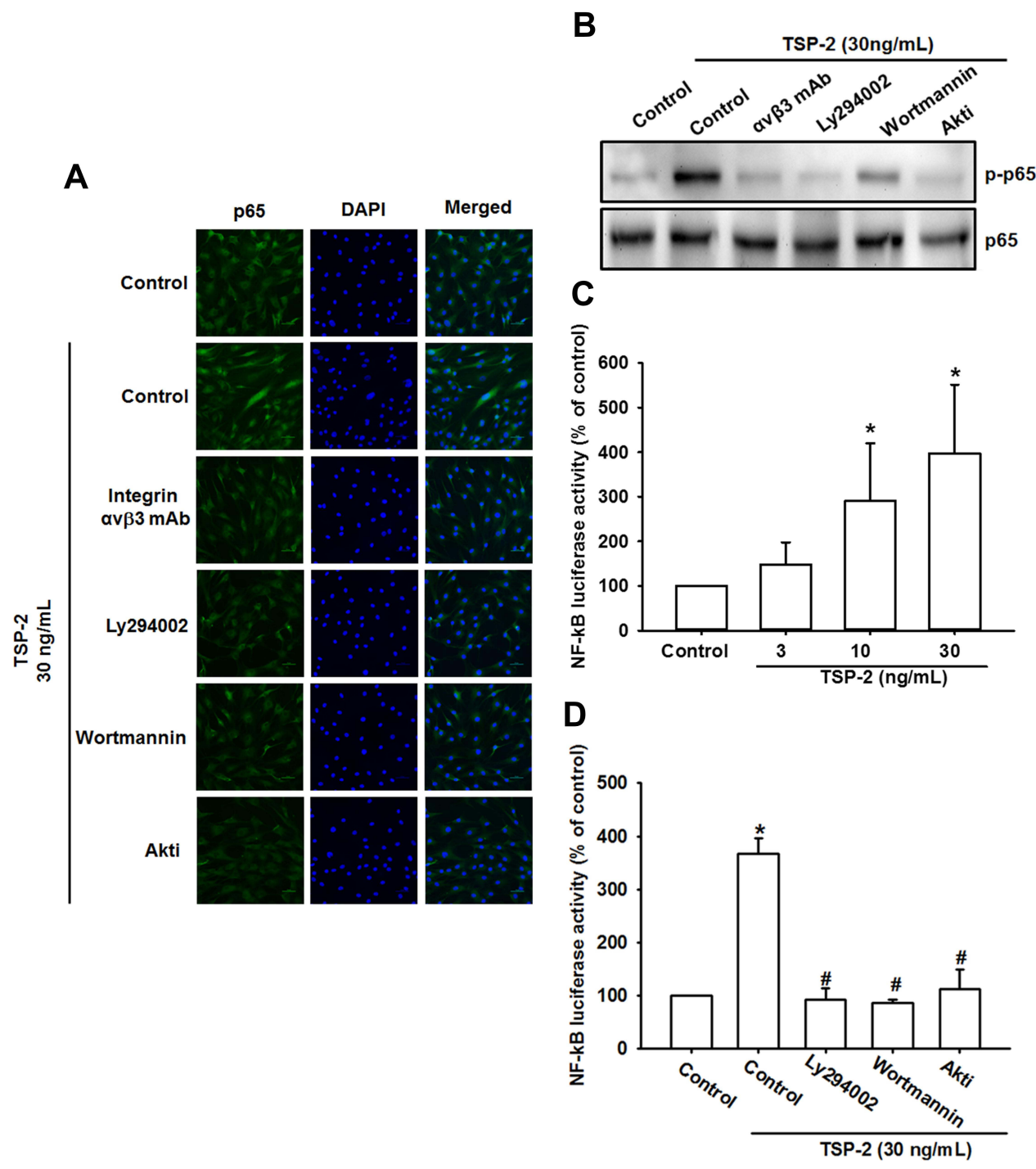

Figure 5 The integrin $\alpha_{v} \beta_{3} /$ PI3K/Akt pathway mediates NF- $\kappa$ B activation in response to TSP2 treatment. (A) OASFs were incubated with integrin $\alpha_{v} \beta_{3}$ mAb, LY294002, Wortmannin, or Aktl for $30 \mathrm{~min}$, followed by incubated with TSP2 $(30 \mathrm{ng} / \mathrm{mL})$ for $60 \mathrm{~min}$. The treated cells were subjected to immunofluorescence staining to detect p65 localization. (B) OASFs were pretreated with integrin $\alpha_{\mathrm{v}} \beta_{3} \mathrm{mAb}$, LY294002, Wortmannin, or Aktl for $30 \mathrm{~min}$, then stimulated with TSP2 (30 $\mathrm{ng} / \mathrm{mL}$ ) for $60 \mathrm{~min}$, and

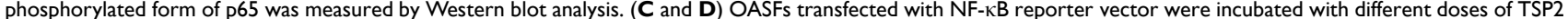
(C) or incubated with TSP2 $(30 \mathrm{ng} / \mathrm{mL})$ in presence of the pathway inhibitor (LY294002, Wortmannin, Aktl, PDTC, or TPCK) (D). The reporter assay was conducted to determine NF- $\kappa B$ transcriptional activation. The $\beta$-galactosidase activity was used as an indicator of transfection efficiency. Results are expressed as the mean \pm SD ( $\geq 5$ ). ${ }^{*} \mathrm{p}<0.05$ compared with controls; ${ }^{*} \mathrm{p}<0.05$ compared with the TSP2-treated group.

Abbreviation: TSP-2, thrombospondin-2.

than NSFs, which explains that OASFs had obvious response to TSP2 stimulation.

The initiation and progression of OA depends upon synovial inflammation, ${ }^{61}$ which produces proinflammatory mediators that contribute to degradation of the cartilage matrix. For example, the expression of IL-1 $\beta$ in synovial cells initiates an inflammatory cascade that leads to joint damage, ${ }^{62}$ while IL-6 perpetuates inflammation and destruction in the synovium. ${ }^{63}$ Moreover, TNF- $\alpha$ contributes to inflammation and joint destruction in RA synovial fluid $^{64}$ and induces ICAM-1 and VCAM-1 expression in endothelial cells. ${ }^{65}$ Here, we found TSP2 neutralized antibody ameliorated ACLT-induced OA model in rats by attenuating articular cartilage degradation and IL-6 expression. However, the other molecules which are involved in OA pathogenesis should be investigated to evaluate the therapeutic effects of TSP2 on OA progression.

An important driver of inflammation is the PI3K/Akt signaling pathway, which mediates many cellular functions, including cell apoptosis, mobility, and autophagic reflux. $^{66}$ By regulating the PI3K/AKT pathway, TSP2 knockdown inhibits the proliferative, migratory, and 
A

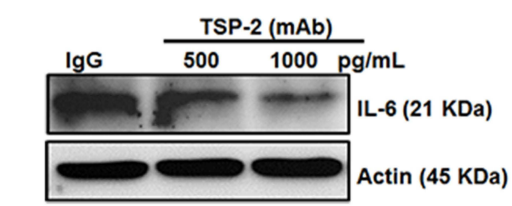

C

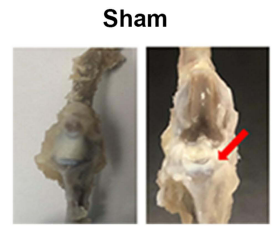

ACLT

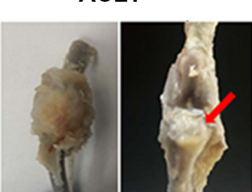

B

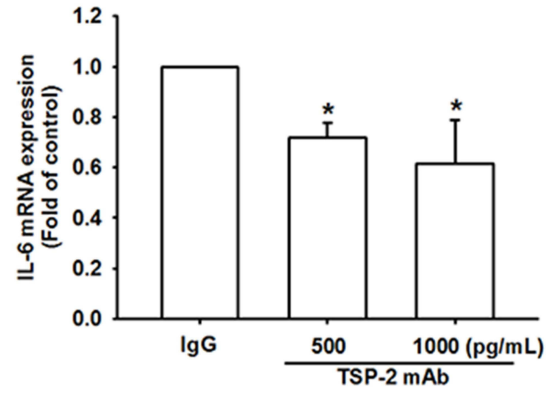

ACLT + TSP-2 mAb

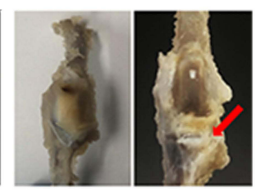

D

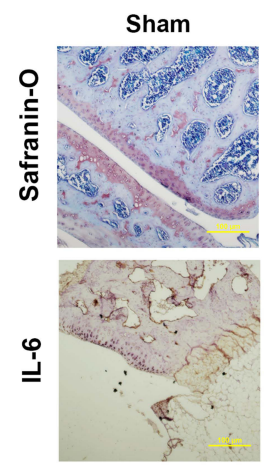

ACLT

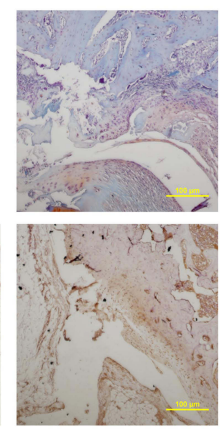

ACLT + TSP-2 mAb

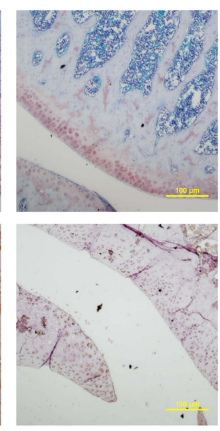

E

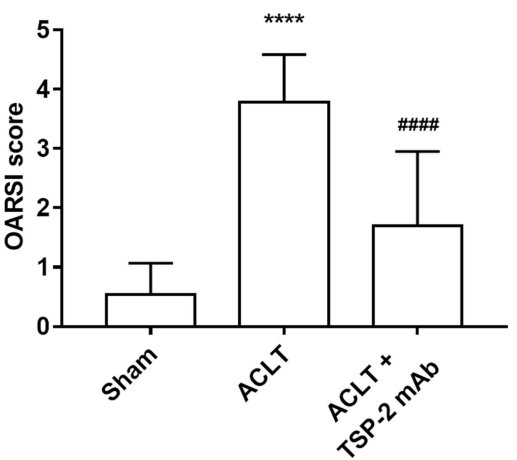

Figure 6 TSP2 neutralizing antibody attenuates ACLT-induced OA in rats. (A and B) OASFs were treated with control lgG or TSP2 neutralizing antibody for 24 h. IL-6 protein and mRNA expression were examined by Western blot and qPCR $(n=5)$. (C) ACLT-induced OA was observed for 8 weeks. The rats were then sacrificed and knee joints were collected and photographed $(n=7)$. Red arrows showed wear and tear of cartilage (D) Paraffin sections of knee joints from each treatment group (sham operation, ACLT, and ACLT treated with TSP2 neutralizing antibody) were stained with Safranin O/ fast green (upper panel) and IHC stain for IL-6 (lower panel). (E) ORASI score of articular cartilage sections stained with Safranin O/ fast green stain was calculated. Results are expressed as the mean \pm SD ( $n=7$ ). * $<0.05$ compared with the lgG groups; ****p < 0.000 I compared with sham group; ${ }^{2}<0.000$ I compared with sham group.

Abbreviations: TSP-2, thrombospondin-2; IL-6, interleukin-6; ACLT, anterior cruciate ligament transection; mAb, monoclonal antibody.

invasive capabilities of gastric cancer cells and facilitates cellular apoptosis. ${ }^{67}$ Our investigation demonstrates that PI3K and Akt inhibitors inhibit TSP2-induced IL-6 expression, while p85 and Akt mutants reduced IL-6 expression in OASFs. Furthermore, the incubation of OASFs with TSP2 upregulated the phosphorylation of $\mathrm{PI} 3 \mathrm{~K}$ and Akt. Our evidence supports the involvement of the PI3K/Akt signaling pathway in TSP2-mediated effects upon IL-6 expression in OASFs.

Since NF- $\kappa \mathrm{B}$ is a major downstream signaling molecule of the PI3K/Akt pathway, ${ }^{68,69}$ we explored the extent of NF- $\mathrm{KB}$ involvement in TSP2-mediated IL-6 production in OASFs. We found that treatment with NF- $\mathrm{KB}$ pathway inhibitors or mutants downregulated TSP2-enhanced IL-6 production. TSP2 treatment of OASFs increased NF- $\mathrm{kB}$ phosphorylation. Following PI3K or Akt inhibitor treatment, TSP2-induced cellular p65 phosphorylation was downregulated, which indicates that TSP2 stimulates the production of IL-6 in OASFs via the PI3K/Akt-NF- $\mathrm{kB}$ signaling cascade.

\section{Conclusions}

In conclusion, thrombospondin-2 increases interleukin-6 production by integrin $\alpha_{\mathrm{v}} \beta_{3} / \mathrm{PI} 3 \mathrm{~K} / \mathrm{Akt} / \mathrm{NF}-\kappa \mathrm{B}$ signal cascade (Figure 7), which gives us more insight into the mechanisms driving osteoarthritis pathogenesis and is expected to assist with the development of more efficacious osteoarthritis therapy. 


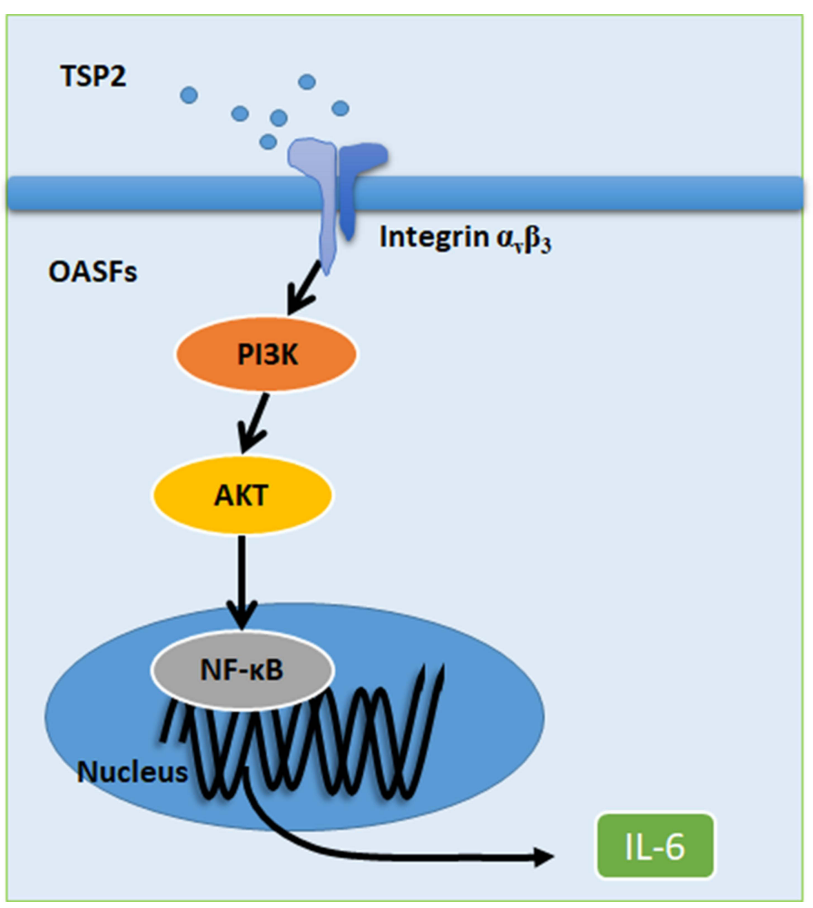

Figure 7 Schematic diagram illustrates the mechanism whereby TSP2 promotes IL6 expression in OASFs. Thrombospondin-2 increases interleukin- 6 production by integrin $\alpha_{v} \beta_{3} / \mathrm{PI}$ I3K/Akt/NF- $\mathrm{KB}$ signal cascade.

\section{Data Accessibility}

The datasets used and analysed in this study are available from the corresponding authors on reasonable request.

\section{Acknowledgments}

This work was supported by grants from Taiwan's Ministry of Science and Technology (MOST-108-2314-B-002-211-MY3, MOST-107-2314-B-341-003, MOST106-2314-B-341-001MY3) and the Shin-Kong Wu Ho-Su Memorial Hospital (SKH-8302-106-0401). We would like to thank Iona J. MacDonald in China Medical University for her English language revision of this manuscript. We thank the staff of the Eighth Core Lab, Department of Medical Research, National Taiwan University Hospital for technical support during the study.

\section{Disclosure}

The authors state no conflict of interest in this work.

\section{References}

1. Cho HJ, Gn KK, Kang JY, Suh KT, Kim TK. Epidemiological characteristics of patellofemoral osteoarthritis in elderly Koreans and its symptomatic contribution in knee osteoarthritis. Knee. 2016;23 (1):29-34. doi:10.1016/j.knee.2015.09.003
2. Lawrence RC, Felson DT, Helmick CG, et al. Estimates of the prevalence of arthritis and other rheumatic conditions in the United States. Part II. Arthritis Rheum. 2008;58(1):26-35. doi:10.1002/art.23176

3. Dillon CF, Rasch EK, Gu Q, Hirsch R. Prevalence of knee osteoarthritis in the United States: arthritis data from the Third National Health and Nutrition Examination Survey 1991-94. J Rheumatol. 2006;33(11):2271-2279.

4. Loeser RF. Aging and osteoarthritis: the role of chondrocyte senescence and aging changes in the cartilage matrix. Osteoarthritis Cartilage. 2009;17(8):971-979. doi:10.1016/j.joca.2009.03.002

5. Krasnokutsky S, Samuels J, Abramson SB. Osteoarthritis in 2007. Bull NYU Hosp Jt Dis. 2007;65(3):222-228.

6. Brandt KD, Dieppe P, Radin EL. Etiopathogenesis of osteoarthritis. Rheum Dis Clin North Am. 2008;34(3):531-559. doi:10.1016/j. rdc.2008.05.011

7. Berenbaum F. Osteoarthritis as an inflammatory disease (osteoarthritis is not osteoarthrosis!). Osteoarthr Cartil. 2013;21(1):16-21. doi:10.1016/j.joca.2012.11.012

8. Zhu M, Chen M, Zuscik M, et al. Inhibition of $\beta$-catenin signaling in articular chondrocytes results in articular cartilage destruction. Arthritis Rheum. 2008;58(7):2053-2064. doi:10.1002/art.23614

9. Gu J, Rong J, Guan F, et al. Association of ADAMTS5 gene polymorphisms with osteoarthritis in Chinese Han population: a community-based case-control study. Rheumatol Int. 2013;33 (11):2893-2897. doi:10.1007/s00296-012-2506-1

10. Glasson SS, Askew R, Sheppard B, et al. Deletion of active ADAMTS5 prevents cartilage degradation in a murine model of osteoarthritis. Nature. 2005;434(7033):644-648. doi:10.1038/ nature 03369

11. Zeng GQ, Chen AB, Li W, Song JH, Gao CY. High MMP-1, MMP-2, and MMP-9 protein levels in osteoarthritis. Genet Mol Res. 2015;14 (4):14811-14822. doi:10.4238/2015.November.18.46

12. Saxne T, Heinegard D. Cartilage oligomeric matrix protein: a novel marker of cartilage turnover detectable in synovial fluid and blood. Br J Rheumatol. 1992;31(9):583-591. doi:10.1093/rheumatology/ 31.9.583

13. Urakami $T$, Manki A, Inoue $T$, Oda $M$, Tanaka $H$, Morishima $T$. Clinical significance of decreased serum concentration of cartilage oligomeric matrix protein in systemic juvenile idiopathic arthritis. $J$ Rheumatol. 2006;33(5):996-1000.

14. Wislowska M, Jablonska B. Serum cartilage oligomeric matrix protein (COMP) in rheumatoid arthritis and knee osteoarthritis. Clin Rheumatol. 2005;24(3):278-284. doi:10.1007/s10067-004-1000-x

15. Koelling S, Clauditz TS, Kaste M, Miosge N. Cartilage oligomeric matrix protein is involved in human limb development and in the pathogenesis of osteoarthritis. Arthritis Res Ther. 2006;8(3):R56. doi:10.1186/ar1922

16. Lohmander LS, Saxne T, Heinegard DK. Release of cartilage oligomeric matrix protein (COMP) into joint fluid after knee injury and in osteoarthritis. Ann Rheum Dis. 1994;53(1):8-13. doi:10.1136/ard.53.1.8

17. Pfander D, Cramer T, Deuerling D, Weseloh G, Swoboda B. Expression of thrombospondin-1 and its receptor CD36 in human osteoarthritic cartilage. Ann Rheum Dis. 2000;59(6):448-454. doi:10.1136/ard.59.6.448

18. Maumus M, Manferdini C, Toupet K, et al. Thrombospondin-1 partly mediates the cartilage protective effect of adipose-derived mesenchymal stem cells in osteoarthritis. Front Immunol. 2017;8:1638. doi:10.3389/fimmu.2017.01638

19. Maly K, Schaible I, Riegger J, Brenner RE, Meurer A, Zaucke F. The expression of thrombospondin-4 correlates with disease severity in osteoarthritic knee cartilage. Int $J$ Mol Sci. 2019;20(2):447. doi:10.3390/ijms20020447

20. Calabro NE, Kristofik NJ, Kyriakides TR. Thrombospondin-2 and extracellular matrix assembly. Biochim Biophys Acta. 2014;1840 (8):2396-2402. doi:10.1016/j.bbagen.2014.01.013 
21. Helkin A, Maier KG, Gahtan V. Thrombospondin-1, -2 and -5 have differential effects on vascular smooth muscle cell physiology. Biochem Biophys Res Commun. 2015;464(4):1022-1027. doi:10.1016/j.bbrc.2015.07.044

22. Liu JF, Lee CW, Tsai MH, et al. Thrombospondin 2 promotes tumor metastasis by inducing matrix metalloproteinase- 13 production in lung cancer cells. Biochem Pharmacol. 2018;155:537-546. doi:10.1016/j.bcp.2018.07.024

23. Bornstein P, Armstrong LC, Hankenson KD, Kyriakides TR, Yang Z. Thrombospondin 2, a matricellular protein with diverse functions. Matrix Biol. 2000;19(7):557-568. doi:10.1016/S0945-053X(00) 00104-9

24. Kyriakides TR, Zhu YH, Smith LT, et al. Mice that lack thrombospondin 2 display connective tissue abnormalities that are associated with disordered collagen fibrillogenesis, an increased vascular density, and a bleeding diathesis. J Cell Biol. 1998;140(2):419-430. doi: $10.1083 /$ jcb. 140.2 .419

25. Taylor DK, Meganck JA, Terkhorn S, et al. Thrombospondin-2 influences the proportion of cartilage and bone during fracture healing. J Bone Miner Res. 2009;24(6):1043-1054. doi:10.1359/ jbmr.090101

26. Jeong SY, Ha J, Lee M, et al. Autocrine action of thrombospondin-2 determines the chondrogenic differentiation potential and suppresses hypertrophic maturation of human umbilical cord blood-derived mesenchymal stem cells. Stem Cells. 2015;33(11):3291-3303. doi: $10.1002 /$ stem. 2120

27. Hankenson KD, Bain SD, Kyriakides TR, Smith EA, Goldstein SA, Bornstein P. Increased marrow-derived osteoprogenitor cells and endosteal bone formation in mice lacking thrombospondin 2 . $J$ Bone Miner Res. 2000;15(5):851-862. doi:10.1359/ jbmr.2000.15.5.851

28. Hankenson KD, Ausk BJ, Bain SD, Bornstein P, Gross TS, Srinivasan S. Mice lacking thrombospondin 2 show an atypical pattern of endocortical and periosteal bone formation in response to mechanical loading. Bone. 2006;38(3):310-316. doi:10.1016/j. bone.2005.08.027

29. Park YW, Kang YM, Butterfield J, Detmar M, Goronzy JJ, Weyand CM. Thrombospondin 2 functions as an endogenous regulator of angiogenesis and inflammation in rheumatoid arthritis. $\mathrm{Am}$ $J$ Pathol. 2004;165(6):2087-2098. doi:10.1016/S0002-9440(10) 63259-2

30. Tang CH, Chiu YC, Tan TW, Yang RS, Fu WM. Adiponectin enhances IL-6 production in human synovial fibroblast via an AdipoR1 receptor, AMPK, p38, and NF-kB pathway. $J$ Immunol. 2007;179(8):5483-5492. doi:10.4049/jimmunol.179.8.5483

31. Chiu YC, Lin CY, Chen CP, et al. Peptidoglycan enhances IL-6 production in human synovial fibroblasts via TLR2 receptor, focal adhesion kinase, Akt, and AP-1- dependent pathway. J Immunol. 2009;183(4):2785-2792. doi:10.4049/jimmunol.0802826

32. Hou CH, Fong YC, Tang CH. HMGB-1 induces IL-6 production in human synovial fibroblasts through c-Src, Akt and NF- $\mathrm{kB}$ pathways. J Cell Physiol. 2011;226(8):2006-2015. doi:10.1002/jep.22541

33. Chen HT, Tsou HK, Hsu CJ, et al. Stromal cell-derived factor-1/ CXCR4 promotes IL-6 production in human synovial fibroblasts. $J$ Cell Biochem. 2011;112(4):1219-1227. doi:10.1002/jcb.23043

34. Yang WH, Chang JT, Hsu SF, et al. Bradykinin enhances cell migration in human chondrosarcoma cells through BK receptor signaling pathways. J Cell Biochem. 2010;109(1):82-92.

35. Gerwin N, Bendele AM, Glasson S, Carlson CS. The OARSI histopathology initiative - recommendations for histological assessments of osteoarthritis in the rat. Osteoarthr Cartil. 2010;18(Suppl 3):S24S34. doi:10.1016/j.joca.2010.05.030

36. Yellin MJ, Winikoff S, Fortune SM, et al. Ligation of CD40 on fibroblasts induces CD54 (ICAM-1) and CD106 (VCAM-1) up-regulation and IL-6 production and proliferation. J Leukoc Biol. 1995;58(2):209-216. doi:10.1002/jlb.58.2.209
37. Chen H, Sottile J, O'Rourke KM, Dixit VM, Mosher DF. Properties of recombinant mouse thrombospondin 2 expressed in Spodoptera cells. J Biol Chem. 1994;269(51):32226-32232. doi:10.1016/S00219258(18)31625-9

38. Chen PC, Tang CH, Lin LW, et al. Thrombospondin-2 promotes prostate cancer bone metastasis by the up-regulation of matrix metalloproteinase-2 through down-regulating miR-376c expression. $J$ Hematol Oncol. 2017;10(1):33. doi:10.1186/s13045-017-0390-6

39. Li Z, Calzada MJ, Sipes JM, et al. Interactions of thrombospondins with $\alpha 4 \beta 1$ integrin and CD47 differentially modulate $\mathrm{T}$ cell behavior. J Cell Biol. 2002;157(3):509-519. doi:10.1083/jcb.200109098

40. Bancroft T, Bouaouina M, Roberts S, et al. Up-regulation of thrombospondin-2 in Akt1-null mice contributes to compromised tissue repair due to abnormalities in fibroblast function. $J$ Biol Chem. 2015;290(1):409-422. doi:10.1074/jbc.M114.618421

41. Chen H, Strickland DK, Mosher DF. Metabolism of thrombospondin 2. Binding and degradation by $3 \mathrm{t} 3$ cells and glycosaminoglycan-variant Chinese hamster ovary cells. J Biol Chem. 1996;271(27):15993-15999. doi:10.1074/jbc.271.27.15993

42. Urtasun R, Lopategi A, George J, et al. Osteopontin, an oxidant stress sensitive cytokine, up-regulates collagen-I via integrin $\alpha \mathrm{V} \beta 3$ engagement and PI3K/pAkt/NFKB signaling. Hepatology. 2012;55 (2):594-608. doi:10.1002/hep.24701

43. Shao G, Liu Y, Ma T, Zhang L, Yuan M, Zhao S. GCN5 inhibition prevents IL-6-induced prostate cancer metastases through PI3K/ PTEN/Akt signaling by inactivating Egr-1. Biosci Rep. 2018;38(6). doi:10.1042/BSR20180816

44. Zhou J, Sun X, Zhang J, Yang Y, Chen D, Cao J. IL-34 regulates IL-6 and IL-8 production in human lung fibroblasts via MAPK, PI3K-Akt, $\mathrm{JAK}$ and NF- $\mathrm{\kappa B}$ signaling pathways. Int Immunopharmacol. 2018;61:119-125. doi:10.1016/j.intimp.2018.05.023

45. Wei L, Xiong H, Li W, Li B, Cheng Y. Upregulation of IL-6 expression in human salivary gland cell line by IL-17 via activation of $\mathrm{p} 38$ MAPK, ERK, PI3K/Akt, and NF-kappaB pathways. J Oral Pathol Med. 2018;47(9):847-855. doi:10.1111/jop.12765

46. Hayami T, Pickarski M, Zhuo Y, Wesolowski GA, Rodan GA, Duong LT. Characterization of articular cartilage and subchondral bone changes in the rat anterior cruciate ligament transection and meniscectomized models of osteoarthritis. Bone. 2006;38 (2):234-243. doi:10.1016/j.bone.2005.08.007

47. Lee $\mathrm{CH}$, Seto WK, Lui DT, et al. Circulating thrombospondin-2 as a novel fibrosis biomarker of nonalcoholic fatty liver disease in type 2 diabetes. Diabetes Care. 2021;44(9):2089-2097. doi:10.2337/dc21-0131

48. Kozumi K, Kodama T, Murai H, et al. Transcriptomics identify thrombospondin-2 as a biomarker for NASH and advanced liver fibrosis. Hepatology. 2021. doi:10.1002/hep. 31995

49. Kimura T, Tanaka N, Fujimori N, et al. Serum thrombospondin 2 is a novel predictor for the severity in the patients with NAFLD. Liver Int. 2021;41(3):505-514. doi:10.1111/liv.14776

50. Deng LY, Zeng XF, Tang D, Deng W, Liu HF, Xie YK. Expression and prognostic significance of thrombospondin gene family in gastric cancer. J Gastrointest Oncol. 2021;12(2):355-364. doi:10.21037/jgo-21-54

51. Peng HY, Chang MC, Hu CM, Yang HI, Lee WH, Chang YT. Thrombospondin-2 is a highly specific diagnostic marker and is associated with prognosis in pancreatic cancer. Ann Surg Oncol. 2019;26(3):807-814. doi:10.1245/s10434-018-07109-6

52. Jiang YM, Yu DL, Hou GX, Jiang JL, Zhou Q, Xu XF. Serum thrombospondin-2 is a candidate diagnosis biomarker for early non-smallcell lung cancer. Biosci Rep. 2019;39(7). doi:10.1042/BSR20190476

53. Wang X, Zhang L, Li H, Sun W, Zhang H, Lai M. THBS2 is a potential prognostic biomarker in colorectal cancer. Sci Rep. 2016;6:33366. doi:10.1038/srep33366

54. MacLauchlan S, Yu J, Parrish M, et al. Endothelial nitric oxide synthase controls the expression of the angiogenesis inhibitor thrombospondin 2. Proc Natl Acad Sci U S A. 2011;108(46):E1137-E1145. doi:10.1073/pnas.1104357108 
55. Roudnicky F, Yoon SY, Poghosyan S, et al. Alternative transcription of a shorter, non-anti-angiogenic thrombospondin-2 variant in cancer-associated blood vessels. Oncogene. 2018;37(19):2573-2585. doi:10.1038/s41388-018-0129-z

56. Lamy L, Foussat A, Brown EJ, Bornstein P, Ticchioni M, Bernard A. Interactions between $\mathrm{CD} 47$ and thrombospondin reduce inflammation. J Immunol. 2007;178(9):5930-5939. doi:10.4049/ jimmunol.178.9.5930

57. Daniel C, Wagner A, Hohenstein B, Hugo C. Thrombospondin-2 therapy ameliorates experimental glomerulonephritis via inhibition of cell proliferation, inflammation, and TGF- $\beta$ activation. Am J Physiol Renal Physiol. 2009;297(5):F1299-F1309. doi:10.1152/ ajprenal.00254.2009

58. Maly K, Andres Sastre E, Farrell E, Meurer A, Zaucke F. COMP and TSP-4: functional roles in articular cartilage and relevance in osteoarthritis. Int J Mol Sci. 2021;22(5):2242. doi:10.3390/ ijms 22052242

59. Tseng S, Reddi AH, Di Cesare PE. Cartilage oligomeric matrix protein (COMP): a biomarker of arthritis. Biomark Insights. 2009;4:33-44. doi:10.4137/BMI.S645

60. Chen FH, Thomas AO, Hecht JT, Goldring MB, Lawler J. Cartilage oligomeric matrix protein/thrombospondin 5 supports chondrocyte attachment through interaction with integrins. $J$ Biol Chem. 2005;280(38):32655-32661. doi:10.1074/jbc.M504778200

61. Goldring MB, Goldring SR. Osteoarthritis. J Cell Physiol. 2007;213 (3):626-634. doi:10.1002/jcp.21258

62. Zheng W, Feng Z, You S, et al. Fisetin inhibits IL- $1 \beta$-induced inflammatory response in human osteoarthritis chondrocytes through activating SIRT1 and attenuates the progression of osteoarthritis in mice. Int Immunopharmacol. 2017;45:135-147. doi:10.1016/j. intimp.2017.02.009
63. Wu X, Cao L, Li F, Ma C, Liu G, Wang Q. Interleukin-6 from subchondral bone mesenchymal stem cells contributes to the pathological phenotypes of experimental osteoarthritis. Am J Transl Res. 2018;10(4):1143-1154.

64. Husby G, Williams RC. Synovial localization of tumor necrosis factor in patients with rheumatoid arthritis. J Autoimmun. 1988;1 (4):363-371. doi:10.1016/0896-8411(88)90006-6

65. Mattila P, Majuri ML, Mattila PS, Renkonen R. TNF alpha-induced expression of endothelial adhesion molecules, ICAM-1 and VCAM-1, is linked to protein kinase C activation. Scand $J$ Immunol. 1992;36(2):159-165. doi:10.1111/j.1365-3083.1992. tb03087.x

66. Martini M, De Santis MC, Braccini L, Gulluni F, Hirsch E. PI3K/ AKT signaling pathway and cancer: an updated review. Ann Med. 2014;46(6):372-383. doi:10.3109/07853890.2014.912836

67. Ao R, Guan L, Wang Y, Wang JN. Silencing of COL1A2, COL6A3, and THBS2 inhibits gastric cancer cell proliferation, migration, and invasion while promoting apoptosis through the PI3k-Akt signaling pathway. J Cell Biochem. 2018;119(6):4420-4434. doi:10.1002/ jcb.26524

68. Sun HZ, Yang TW, Zang WJ, Wu SF. Dehydroepiandrosteroneinduced proliferation of prostatic epithelial cell is mediated by NFKB via PI3K/AKT signaling pathway. J Endocrinol. 2010;204 (3):311-318. doi:10.1677/JOE-09-0270

69. Zhang XY, Liu Y, He T, et al. Anaphylatoxin C5a induces inflammation and reduces insulin sensitivity by activating TLR4/NF-kB/PI3K signaling pathway in 3T3-L1 adipocytes. Biomed Pharmacother. 2018;103:955-964. doi:10.1016/j.biopha.2018.04.057
Journal of Inflammation Research

\section{Publish your work in this journal}

The Journal of Inflammation Research is an international, peerreviewed open-access journal that welcomes laboratory and clinical findings on the molecular basis, cell biology and pharmacology of inflammation including original research, reviews, symposium reports, hypothesis formation and commentaries on: acute/chronic inflammation; mediators of inflammation; cellular processes; molecular mechanisms; pharmacology and novel anti-inflammatory drugs; clinical conditions involving inflammation. The manuscript management system is completely online and includes a very quick and fair peerreview system. Visit http://www.dovepress.com/testimonials.php to read real quotes from published authors. 